\title{
A confrontação de Fichte com o realismo racional de Reinhold e Bardili. Perspectivas práticas
}

Federico Ferraguto

\section{(2) OpenEdition \\ Journals}

Edição electrónica

URL: http://journals.openedition.org/ref/708

ISSN: 2258-014X

\section{Editora}

EuroPhilosophie Editions

\section{Refêrencia eletrónica}

Federico Ferraguto, «A confrontação de Fichte com o realismo racional de Reinhold e Bardili.

Perspectivas práticas », Revista de Estud(i)os sobre Fichte [Online], 13| 2017, posto online no dia 01 março 2017, consultado o 08 setembro 2020. URL : http://journals.openedition.org/ref/708

Este documento foi criado de forma automática no dia 8 setembro 2020

(c) EuroPhilosophie 


\title{
A confrontação de Fichte com o realismo racional de Reinhold e Bardili. Perspectivas práticas
}

\author{
Federico Ferraguto
}

\section{Realismo racional e escola fichteano-schellinguiana}

1 "Encontro no livro dele uma representação do seu idealismo transcendental completamente nova, ou, mais propriamente, a invenção do mesmo de uma maneira nova, em uma via completamente diferente... e, apesar da letra, encontro de volta o seu espírito" (BW, 83). Em janeiro de 1800 Reinhold transcrevia este trecho de uma carta a Fichte em uma outra carta para Bardili, apontando que a distancia entre os dois filósofos seria devida apenas ao escasso conhecimento que Bardili tinha da doutrina da ciência.

2 É notório o fato de que Fichte recusa a aproximação reinholdiana entre realismo racional e doutrina da ciência, e o quanto, já na resenha do Grundriss der ersten Logik (de agora em diante GEL), busque afastar-se da perspectiva filosófica que primeiro Bardili, e depois Reinhold, com os Beyträge de 1801-1803 (de agora em diante BLU), estavam propondo no debate filosófico sobre o destino e os desenvolvimentos possíveis do kantismo.

3 Apesar do afastamento critico de Fichte, porém, a perspectiva aberta por Bardili e Reinhold corresponde a um projeto amplo, que o primeiro amadurece em insólita autonomia e o segundo busca ligar com as perspectivas teóricas abertas pela polêmica sobre o ateísmo de Fichte e à questão em torno da possibilidade de repensar, de um ponto de vista mais amplo, os nexos conceituais da própria doutrina da ciência fichteana.

4 Nos Beyträge Reinhold divulga a perspectiva teórica de Bardili, conectando-a à exigência geral da filosofia de encontrar uma verdade real e originária, que fica atrás do saber (BLU, I, X-XI). Ao fazer isso, Reinhold alia-se com Jacobi e direciona-se criticamente 
para com uma posição filosófica virtual - a "escola fichteano-schellinguiana" (fichtischschellingsche Schule) - que sintetiza de maneira geral posições de Fichte e de Schelling, nem sempre distinguidas com o devido cuidado e nem sempre avaliadas nas suas especificidades $^{1}$. A crítica de Reinhold à escola fichteano-schellinguiana concerne essencialmente a três pontos. O primeiro tem a ver com a busca do princípio da filosofia. Para Reinhold o problema de Fichte e Bardili não seria tanto a redução da filosofia à investigação lógico-formal, e sim a identificação entre saber e ser, que tenderia a ocultar a transcendência real do princípio e o interpretaria como o resultado de uma prestação intelectual do sujeito. 0 segundo envolve a compreensão da natureza. A rebaixamento do princípio do saber e da realidade a uma prestação subjetiva, reduziria também a natureza a simples emanação da própria subjetividade. Desse ponto de vista, o eu põe o mundo apenas na medida em que põe a si mesmo. E filosofar sobre a natureza não seria nada, senão criá-la.

Essa última conclusão aparece, no entanto, apenas como a consequência dos resultados obtidos em um terceiro âmbito em que se desenvolve a confrontação de Reinhold com a escola fichteano-schellinguiana: os fundamentos da filosofia prática. A redução do pensamento à prestação subjetiva, de fato, levaria a identificar a liberdade, pressuposta no desenvolvimento da filosofia transcendental, com o arbítrio individual e reduziria a própria filosofia transcendental, ciência filosófica e supostamente pura, rigorosa e válida universalmente, a uma expressão de um mero amor de si e de um empirismo insuficiente, seja no plano epistemológico, seja no axiológico. Essa crítica é influenciada com certeza pelos resultados da crítica jacobiana a Fichte, apresentada no Nihilismusbrief, Mas não apenas isso. De fato, tanto a crítica de Reinhold, como a resposta - explícita e implícita - de Fichte marcam uma reflexão mais geral sobre a possibilidade de integrar de modo certo fato e razão e, no caso, a estrutura do impulso sensível, elemento fático que motiva o saber em sua concretude, no horizonte de uma razão que se manifesta no sujeito, mas não coincide com as suas prestações práticoteoréticas.

6 Trata-se de uma questão que tem efeitos na reflexão sobre as estruturas especulativas do saber filosófico, na reflexão sobre as modalidades para compreender a transcendência que se manifesta no saber e na discussão acerca das modalidades epistêmicas para alcançá-lo, e em especial o conceito de fé. Entre o fim do século XVIII e o começo do XIX essas questões representam, como sabemos, horizontes problemáticos decisivos para refletir em torno da relação entre idealismo e realismo, em torno da possível integração dessas duas perspectivas e, nesse sentido, em torno da saída de um suposto idealismo absoluto, seja ele entendido feito um labirinto, seja ele assimilado a uma clareza rarefeita e gelada, como a "cima do Monte Branco", capaz de congelar toda forma de realidade e alteridade contraposta ao próprio eu, conforme alega Jean Paul na Clavis fichtiana seu leibgeberiana (Richter, 2003, p. 66).

7 No presente artigo tentarei esclarecer esse terceiro ponto de confrontação entre Bardili, Reinhold e Fichte. Começarei apresentando a crítica de Reinhold ao conceito fichteano de autonomia ( $(2)$. Irei, depois, evidenciar o horizonte especulativo reinholdiano a partir do realismo de Bardili (§ 3). Por fim tentarei trazer à tona a resposta fichteana às criticas de Reinhold levando em conta duas duplas conceituais: a relação entre fé e arbítrio (§ 4) e a entre autonomia e impulso (§ 5). 


\section{Um prazer sublimado.}

8 No ensaio Ueber die Autonomie als Princip der praktischen Philosophie der kantischen - und der Fichtisch-schellingschen Schule, Reinhold atribui a Kant o mérito de ter encontrado na autonomia da vontade o sentido e o fundamento da lei moral e da independência da razão prática. $O$ grande mérito de Fichte seria, mais a frente, o de ter tornado a autonomia da vontade, não apenas o princípio da razão prática, e sim da filosofia toda. Já no postulado da doutrina da ciência, assim como aparece na Erste Einleitung - pensar um objeto e desviar o olhar do objeto para pensar o próprio pensamento - Fichte teria trazido à tona a espontaneidade subjetiva evidenciada nessa dinâmica e a teria entendida como o horizonte independente de um dado pressuposto em que deduzir as ações necessárias do espírito humano. Fichte teria então assimilado demasiado rapidamente a autonomia kantiana e a espontaneidade evidenciada no postulado (a Tathandlung), igualando isto, que para Kant seria um fato da razão com a capacidade que permite compreendê-lo. Em termos kantianos, Fichte igualaria a ratio cognoscendi da liberdade e ratio essendi da lei moral, desconsiderando a tensão produtiva entre elas. Essa assimilação, para Reinhold implícita em Kant, levaria a interpretar a lei moral como uma autodeterminação da vontade. Essa última teria que ser vista como uma liberação da espontaneidade subjetiva de toda vinculação objetiva e como expressão de um ímpeto (Schwung) que leva o eu a se afirmar como o absolutamente positivo e consciente de si mesmo. Desta maneira se cumpriria, porém, a traição idealística da exigência e da tarefa (Aufgabe) fundamental da filosofia: fundamentar a realidade do conhecimento através da construção do saber filosófico, sem anulá-la nele mesmo (BLU, I, 3-5).

9 Para Reinhold, que já tinha refletido longamente sobre a questão há uma dezena de anos no segundo tomo das Cartas sobre a filosofia kantiana, a redução do princípio do saber a uma determinação da vontade implicaria, de fato, a recondução da liberdade a uma determinação do arbítrio individual ${ }^{2}$. No contexto da escola fichteanoschellinguiana, a lei absoluta da liberdade não seria por si mesma moral. Ela se tornaria moral graças a uma escolha do arbítrio que, conforme observa Schelling na Allegemeine Uebersicht (em que Reinhold baseia a sua interpretação crítica) contrapõe a lei da liberdade aos impulsos sensíveis, tornando-a lei moral ${ }^{3}$.

10 A autonomia kantiana seria, portanto, a manifestação de uma "autonomia verdadeira e autêntica", identificada com uma pura espontaneidade subjetiva, ou com um pura transcendentalidade, a qual, porém, poderia ser compreendida apenas como epifenômeno de uma determinação individual e arbitrária ${ }^{4}$.

11 Alegar que a autonomia seja a consequência do arbítrio significa, no entanto, negá-la. 0 arbítrio, enquanto tal, pode estar definido como um agir condicionado do prazer e do desprazer e, neste sentido, não seria sequer autônomo, sendo ele motivado por um impulso sensível (BLU, II, 114). A formação da filosofia transcendental, portanto, mais do que a um desenvolvimento necessário, orgânico e acabado, corresponderia a uma "ilusão psicológica", consistente em uma "sublimação" de determinações empíricas e contingentes, que pertencem ao individuo filosofante, em estruturas necessárias da razão (BLU, II, 128) .

12 Reduzido a uma determinação arbitrária, o esforço para um conhecimento completamente fundado se encurtaria na satisfação de um impulso originado pelo sentimento de prazer e desprazer, que representaria a verdadeira fonte - psicológica e 
antropológica - da razão especulativa teorizada por Fichte e Schelling. Ambos dedicarse-iam, para Reinhold, à busca do "prazer da independência do prazer e do desprazer em geral - e do desprazer para o prazer e o desprazer", para ultrapassar "o arbítrio em geral, ou seja, si mesmos em uma construção imaginativa" (Einbildung; BLU, II, 117-118). O sujeito da filosofia especulativa poderia assim fantasiar uma liberdade plenamente espontânea e criadora das determinações da experiência externa e, através do desenvolvimento metódico da ilusão psicológica (methodische Schein), reconduziria tudo à sua autoatividade e ao seu domínio.

Seria portanto inconsequente sustentar, como faz Fichte no ensaio Sobre o fundamento da nossa fé em um governo divino do mundo, que o agir do filósofo faria sentido apenas na forma de um agir na fé ou de uma fé no agir (BLU, II, 127; GA, I, 5, 354) ${ }^{6}$. De fato, o filósofo transcendental, na medida em que considera a si mesmo como autônomo, recusa a abertura ao transcendente e, com isso, a possibilidade da fé. Por outro lado, como ele admite a possibilidade da fé, reconhecer-se-ia como ser sensível, dependente e finito. Com isso, porém, ele negaria o pressuposto de todo seu filosofar. O filósofo transcendental, portanto, encontrar-se-ia diante do Abgrund des sich losreissendes Selbstes, que, conforme Reinhold, não pode ser ultrapassado, nem por meio do seu agir moral, nem graças a seu pensamento puro (BLU, II, 139). De fato,

O ser humano poderia ultrapassar aquele abismo apenas em parte por meio do agir religioso, em sentido próprio, que é autêntica renúncia a si mesmo e graças ao qual ele vê Deus e a natureza apenas através de Deus, e, em parte apenas se levantando até aquele pensar que nasce, na consciência humana, apenas pelo verdadeiro absoluto e só volta para ele, que de todo modo e com certeza tem Deus diante de si e que, apenas nessa medida, é verdadeiro pensamento no ser humano - revelação do verdadeiro originário no verdadeiro e do verdadeiro através do verdadeiro originário. Apenas esse pensamento - e aquele agir - poderiam ser ditos morais (BLU, II, 139-140).

Autônomo, portanto, não seria quem pensa em reconduzir tudo para si mesmo, e sim quem reconhece a sua dependência estrutural por isto, que o constitui na sua finitude, representando a raiz autêntica do seu agir e pensar, que se revela nele, mas não pode ser deduzida por ele.

\section{0 impulso durch die Materie}

Na sua crítica à escola fichteano-schellinguiana Reinhold retoma essencialmente isto, que já tinha discutido na sua Carta a Lavater e Fichte (Reinhold, 1799, 23-24, 71) ${ }^{7}$. Só que, enquanto em 1799 ele confiava ao senso comum a abertura para o outro de si, contra a autonomia reivindicada, mas não praticada, pela filosofia transcendental, em 1801 encontra em Bardili uma ancoragem especulativa mais sólida. Em 1801, de fato, a finitude, a que apela Reinhold, não é mais determinada pelo conceito genérico de verdadeiro, típico da carta ${ }^{8}$. O filósofo de Kiel fala, ao invés, de uma finitude definida pela revelação de uma realidade absoluta (o verdadeiro originário) no pensamento conseguinte e acabado (o verdadeiro), conforme um desenvolvimento analítico que leva do princípio absoluto até as suas manifestações na natureza. 0 argumento que Reinhold contrapõe à escola fichteano-schellinguiana, de fato, envolve duas teses. A primeira: a racionalidade humana acabada (o verdadeiro) é o horizonte em que se revela uma realidade que a transcende e a fundamenta (o verdadeiro originário). A segunda: essa 
revelação acontece em conformidade ao desenvolvimento do saber que a razão tem de si mesma (o verdadeiro originário revela-se através do verdadeiro).

Bardili, de fato, propõe no Grundriss e no Briefwechsel über das Wesen der Philosphie (de agora em diante BW) com Reinhold publicado por este ultimo em 1804, uma nova versão do kantismo, que permite dar conta dessas conclusões e em que a relação da razão com um objeto não está descrita a partir da síntese entre mente e mundo, e sim da relação da razão com si mesma, que ele esclarece como relação entre pensamento absoluto e aplicação do pensamento para si mesmo. Assim o autor do Grundriss acredita ter demonstrado que a relação cogniscitiva e prática entre sujeito e objeto seja justificável, não em base às prestações intelectuais do próprio sujeito, e sim analiticamente na própria estrutura da racionalidade. $O$ próprio pensamento seria exibição de uma realidade fundamental e sempre igual a si mesma, da qual se gerariam as articulações específicas da razão humana, desde os estímulos sensíveis até as capacidades de elaboração conceitual deles (GEL, 3). Na repetição e no ficar sempre igual a si mesmo na própria repetição, o pensamento gera a relação intencional com um objeto e define o saber como sensatez geral da realidade, mais do que como um instrumento para a espontaneidade subjetiva controlar um dado pressuposto. Numa relação crítica, mas não necessariamente negativa com Kant ${ }^{9}$, Bardili busca mostrar como pensamento e mundo, mais do que elementos reais e distintos, sejam perspectivas de determinação do desenvolvimento de uma racionalidade unitária, que os precede e os fundamenta ${ }^{10}$.

De fato, à altura da explicação filosófica não é possível evitar definir a gênese da consciência intencional a partir de um estímulo sensível (BW, 24) ou, mais especificamente, de um "impulso mediante da matéria" (Trieb durch die Materie, GEL, 105), imediato e inconcebível. E seria igualmente inevitável entender esse impulso como o instrumento fundamental para construir o conceito de individualidade, tal como um ser vital, que se desenvolve ao longo do tempo e através de uma sequência e uma integração de representações concretas (GEL, 109; BW, 27). Entretanto, para além da fenomenologia da consciência concreta que pode ser esboçada desse ponto de vista, o impulso, não representa um elemento fático e não deduzível, mas tem que ser compreendido apenas como uma disponibilidade formal da razão (i.e. do pensamento) ${ }^{11}$, não a ficar limitada externamente (isto, que para Bardili seria absurdo), mas a particularizar-se analiticamente na consciência intencional de um objeto (BW, 26). De fato, o suporte material em que o pensamento se revela (o impulso mediante da matéria), tem que ser entendido como traço fundamental de uma multiplicidade, não dada, mas analiticamente implícita na repetição necessária da unidade absoluta e real do pensamento (GEL, 3-4).

Essa unidade real (que Bardili chama de Deus, razão, pensar absoluto, Prius), que se revela na consciência intencional, não pode ser interpretada a partir das formas espaço-temporais da nossa experiência, que a entenderiam em função da sua possibilidade ou impossibilidade objetiva. Essa unidade tem que ser entendida como um "verdadeiro ser, necessário imutável e incapaz de exceções e limitações; o não pensá-lo ou o pensar de modo diferente seria uma contradição" (GEL, 92).

19 Nesse contexto especulativo, até a importância do suposto ateísmo de Fichte teria que ser rebaixada. Em seu alcançar Deus como ordem moral do mundo, Fichte teria visto a diferença fundamental entre ser e pensamento subjetivo. No entanto, a sua lealdade ao ponto de vista kantiano teria simplesmente levado ele a recusar a sua existência, sem 
voltar a afirmá-la em termos de realidade verdadeira, originária e inconcebível, que se revela à consciência humana, à medida que compreende a si mesma como capacidade de pensar. Justamente através dessa admissão, pelo contrário, a visão da realidade oferecida pelo realismo racional impede identificar a determinação arbitrária da vontade e a lei moral. A determinação arbitrária, de fato, pode ser pensada à luz de uma "condição de possibilidade" (BW, 24) que se dá na nossa consciência e que não poderíamos construir sem tê-la já incluída como pressuposto da nossa argumentação. Trata-se, porém, de compreender como pensar a possibilidade fundamental do pensamento e, sobretudo, de encontrar uma maneira para justificar nossas afirmações em torno dela. E justamente sobre esse ponto que Fichte manifesta a sua perplexidade acerca do pensamento de Bardili e parece, como veremos nos parágrafos seguintes, repensar de maneira mais afinada as mesmas questões discutidas por este último.

\section{Fé e arbítrio na doutrina da ciência de 1805}

Não obstante a explícita desconfiança e uma clara postura crítica, seja para com Bardili, na resenha do Grundriss, seja para com Reinhold, no Antowortschreiben, Fichte partilha duas exigências do realismo racional: a primeira consiste na compreensão do saber como constituído pelo apresentar-se o pelo repetir-se de uma razão unitária em todo saber determinado (GA I, 6, 437-8). A segunda consistiria na de reconduzir todo saber determinado a um ser puro e intelectual (GA I, 6, p. 438), apesar de esse ser estar compreendido apenas à luz da reflexão concreta e não em relação a um mero axioma lógico-formal. Para Fichte, de fato, Bardili não falha em justificar essas duas exigências. O seu erro consistiria em postular o pensamento puro como condição de possibilidade do representar concreto, sem fornecer uma justificação da maneira em que o pensa justamente a partir das operações da consciência efetiva. 0 pensamento seria, sim, a condição fundamental para nós acessarmos o mundo. Mas isto não significa que seja suficiente formular essa afirmação para tê-la justificada. De fato, seria necessário explorar o saber concreto e mostrar a gênese dele a partir do fato que a referência para com o próprio ser torna compreensível (GA II, 9, 5).

21 A tentativa de acolher as críticas de Reinhold e Bardili, reestruturando-as a partir do ponto de vista da doutrina da ciência aparece evidente na exposição de 1805, onde Fichte esclarece que todo pensamento do ser é projeção do ser, i. e. transfiguração necessária do ser pensado na sua existência discursiva. Pensar energicamente o ser, ou seja, evidenciar a ideia de ser implícita em todo saber, não significa transcender a existência dele, e sim afirmar a diferença entre ser e existência, dando conta do fato de que essa diferença só pode ser entendida no espaço aberto pela própria existência. Isso significa que temos que distinguir, no mesmo sentido de Bardili, entre construção efetiva da consciência intencional e a sua condição fundamental de possibilidade. Mas essa distinção faria sentido apenas à luz do discurso que a efetiva, o qual, por sua vez, tem que ser esclarecido na sua estrutura e justificado nas suas condições. A distinção entre ser e existência, de que tudo depende na filosofia transcendental (GA, II, 9, 187), envolve o "nós" que opera essa distinção, o qual tem que ser compreendido inicialmente como expressão de uma determinação arbitrária.

O conjunto de práticas necessárias para esclarecer essa autodeterminação tem que ser descrito de dois pontos de vista que, contudo, não ameaçam a unidade da investigação de Fichte. Por um lado, a referência necessária às faculdades psicológicas e ao arbítrio 
do indivíduo filosofante expressa o traço ativo e poiético do próprio indivíduo que constrói a doutrina da ciência e, nesse sentido, Fichte parece apoiar a descrição reinholdiana do processo de formação do filosofar na 'escola fichteano-schellinguiana'. Por outro lado, porém, Fichte mostra, com Reinhold, e para além de Reinhold, como o proceder necessário da doutrina da ciência implica uma renúncia a si mesmo do indivíduo diante da lei que torna possível o próprio desenvolvimento da descrição transcendental. No mesmo sentido de Bardili (BW, 24) Fichte entende o desenvolvimento da consciência concreta como um Nichts diante da condição de possibilidade que justamente esse desenvolvimento permite alcançar. A dinâmica, ativa e passiva ao mesmo tempo, ligada à relação entre o saber e a sua condição fundamental pode ser articulada em quatro momentos fundamentais, que Fichte mantém, se bem com variações consistentes, nas exposições sucessivas da doutrina da ciência:

1. O exercício do arbítrio na produção do discurso filosófico cria o fundo necessário para compreendermos a diferença entre ser e existência, mas não esgota as potencialidades da filosofia em alcançar o princípio que a deixa existir. A representação do discurso filosófico tem que compreender a si mesma, mas também tem que se anular diante da lei que a fundamenta (GA, II, 9, 182) e justamente ao longo da penetração transcendental do arbítrio envolvido na formulação do teorema de partida da doutrina da ciência: "o saber é em si a existência absoluta ... ou a existência do absoluto" (GA, II, $9,185)$.

2. A atitude epistêmica pressuposta no exercício do arbítrio é uma "fé", ou um "dar crédito" a isto, que está afirmado pelo teorema fundamental. A fé, porém, tem que ser justificada, ou seja, integrada reflexivamente nas opções que a reflexão filosófica pode aproveitar para alcançar as determinações da razão na clareza das suas conexões (GA, II, 9, 232).

25 3. Essa fé tem que ser praticada. O que está exposto através da hipótese tem que ser completamente desenvolvido, de maneira gradativa e sem intervenções de atitudes dóxicas que desviam o plano de imanência aberto pelo teorema. Quem constrói a doutrina da ciência tem que sacrificar o seu si-mesmo individual e abandoar-se ao decorrer gradativo das conexões que se apresentam a partir do próprio teorema (GA, II, $9,238)$.

4. Sacrificar o próprio si-mesmo individual significa reconhecer a lei implícita no teorema, reconhecê-la como válida e esclarecer que a hipótese assumida arbitrariamente é fruto de um "agir livre", ou seja, de um ato que expressa a exigência apresentada pela lei operante na própria hipótese (GA, II, 9, 261).

O desenvolvimento genético da doutrina da ciência de 1805 mostra, então, como arbítrio, fé, sacrifício e liberdade representem elementos que emergem em função do reconhecimento da essência do saber como expressão de uma lei, indicam mais do que simples fatores extra-filosóficos ou performativos que motivam o desenvolvimento imanente do saber ${ }^{12}$. Fichte parece nesse sentido querer neutralizar a crítica reinholdiana. É verdade que a doutrina da ciência parte de uma determinação arbitrária. Mas essa determinação é a condição para praticar uma fé, por Reinhold apenas exigida, que consiste justamente em renunciar a si mesmo em função de uma possibilidade aberta, mas não produzida, fundada, ou justificada, pelo próprio arbítrio.

Por meio da fé, de fato, é possível deixar a busca transcendental se desenvolver para além da problematicidade do seu pressuposto essencial e confirmá-lo, não em uma dedução analítica, como acontece em Bardili, e sim por meio da prática efetiva do 
próprio saber. A fé não tira as potencialidades reflexivas do saber, mas confirma a função da reflexão na dedução completa que o saber faz das suas próprias determinações, abrindo o arbítrio envolvido na construção concreta do saber transcendental à necessidade das suas conexões ou, na linguagem fichteana, à necessidade da sua lei. A lei aparece como um elemento que não é mais assumido problematicamente, e sim alcançado imediatamente como expressão do fato que deixa existir o próprio saber transcendental. Esse, que Fichte chama de Factum fiens (GA II, 9, 287-288) não é uma causa ou um ser pressuposto, mas uma vida. Fichte pode assim esclarecer isto, que para Reinhold era um absurdo, ou seja, o fato de que o agir do filósofo é um agir na fé, determinado por uma abertura estrutural do saber para o outro de si. o desafio da doutrina da ciência consiste justamente na tentativa de conciliar a auto-imanência do saber com a sua abertura para uma alteridade que entra no próprio saber apenas indiretamente, como a sua lei ou como a exigência que o orienta. A questão seria agora a de entender de qual forma, essa abertura pode acontecer, ou seja, de qual forma o absoluto pode manifestar-se no saber, sendo ele configurado como a sua lei.

\section{0 Trieb des Seins}

Para esclarecer essa questão, na exposição da doutrina da ciência de 1804-II Fichte introduz a teoria do impulso do ser (Trieb des Seins) retomando as suas implicações na exposição de 1807. Essa teoria, que desloca o conceito de Trieb de uma maneira aparentemente diferente daquela do desenvolvimento da primeira doutrina da ciência de Jena ${ }^{13}$, tem a função de neutralizar as críticas do realismo racional e de distinguir o ponto de vista da doutrina da ciência fichtiana daquele da filosofia da natureza de Schelling, a que Fichte estava assimilado pelo Reinhold dos Beyträge. Visto à luz da lei que regra o saber, o fato que o deixa ser pode ser reconfigurado como um Seyn (GA, II, $10,165)$. Um ser fechado em si mesmo, caracterizado por uma dinamicidade imanente, de fato, pode ser compreendido como um impulso a sair fora de si (GA, II, 8, 264). Na segunda exposição da doutrina da ciência de 1804 (Lição XXVI), esse impulso não intervém como um simples elemento fático que permite alcançar a gênese da representação, nem como uma determinação antropológica que permite a construção individual do saber filosófico. Fichte fala justamente de um Trieb des Seins (de um impulso do ser, GA, II, 8, 261) e o entende como o correlato fundamental da certeza que o saber tem de si mesmo como vida figurativa do absoluto. Saber algo significa estar certo disto que se sabe e do fato de que se sabe. Essa certeza implica a anulação do saber diante disto, que ele sabe e, portanto, a posição de um ser. Porém, como o ser posto se dá apenas através do próprio saber, esse ser não é um objeto dado, e sim o próprio saber como ser posto, i.e. uma expressividade dinâmica, vista, não como atividade produtiva, e sim como uma força imanente e detida, que não se concretiza em uma atividade causal real. o impulso, portanto, é o índice da imanência absoluta do saber ou, com as palavras de Fichte, a expressão mais apropriada para definir a sua "autonomia", que podemos descrever formalmente como autorreflexão, e que materialmente, só pode ser vivida no próprio ato que o constrói (GA, II, 8, p. 265).

Uma argumentação muito parecida é retomada na exposição de 1807 (Lições XIX-XXII) e empregada, de maneira análoga à exposição de 1804, para definir a relação entre ser e saber. A absoluta imanência do saber, levantada já em 1804, é aprofundada em 1807 em 
duas direções. A primeira leva até uma compreensão da doutrina da ciência como um realismo autêntico. A identificação entre vida imanente do saber é possível apenas internamente ao saber, que se vê e se projeta como um objeto e, como em 1804, pode ser definida como um impulso. Na medida em que alcança o seu ser vital, como o cerne do seu desenvolvimento, a doutrina da ciência pode definir a si mesma como um realismo. A realidade que ela afirma, porém, não é a de um objeto dado, ou a problemática de um ser admitido hipoteticamente e justificado, como queriam Reinhold e Bardili, "por meio de uma conclusão a partir de certas premissas" (GA, II, 10, 165). Trata-se, pelo contrário, da realidade do próprio saber, na sua vida imanente, ou na sua pura tendência a sair de si mesmo. Como essa tendência é justamente um impulso, ela não se explica como causalidade "por meio (durch) do mero ser... mas através do ver", ou seja, com referencia às potencialidades figurativas do saber, pois a tendência a sair de si mesmo fica virtual, ou seja, se torna um mero esquema de uma realidade e não algo real em si mesmo. Por consequência, os traços fundamentais do saber concreto - a intuição sensível, assim como, em geral, a representação - não são estimuladas por algo externo, e nem aparecem como o produto da exigência formal de pensar o real feito uma sequência de momentos, conforme achava Bardili. Eles são, sim, reflexo do impulso como vida imanente ao ver e, em especial, são o correlato da repetição e do projetar-se do saber em relação a si mesmo enquanto ser. Apenas nessa altura, ou seja, apenas em consequência da auto-aplicação do saber, o ser, ou melhor, o saber posto como ser, ou seja, como vitalidade absoluta e imanente a si mesma, se revela no saber que sabe de si mesmo e objetiva a si mesmo. Apenas nesse sentido seria possível retomar os conceitos, de origem teológica, de revelação e criação. Revelação, no sentido de manifestação acabada da vida do saber no próprio saber autorreflexivo. Criação, no da gênese da estrutura da consciência intencional, como expressão dessa manifestação acabada (GA, II, 10, 171).

31 A segunda direção em que Fichte retoma a teoria do impulso apresentada em 1804 tem a ver com a descrição da própria estrutura interna do impulso e com a sua diferenciação do impulso sensível. Na sua estrutura formal, de fato, o impulso do ser pareceria análogo ao sensível. A sua causalidade detida é caraterizada por uma afeição. Essa afeição, porém, não remonta em uma carência insatisfeita ou, como queria Reinhold, sublimada. A afeição define a própria estrutura do saber como algo essencialmente dependente de um outro de si e, nesse sentido, a vida do saber pode ser compreendida como auto-afeição dele. O saber, de fato, fica um "ser fora do ser" (GA, II, 10,170 ), ou seja, um ver, que tem uma consistência ontológica, limitada ao ficar projeção virtual da dinamicidade interna do ser "conforme a sua essência necessária" (GA, II, 10,169).

32 Portanto o impulso do ser, como um traço básico e imanente à estrutura do saber, não poderia ser igualado, nem a um impulso sensível (Reinhold), pois não pertence à constituição epistemológica do sujeito, nem a um impulso através da matéria (Bardili), pois não representa uma exigência formal para a repetição do pensamento, e nem como um "impulso originário", ou alma do mundo (Schelling), pois, como Fichte escreve na carta a Schelling de 31.05.1801, não representa a força escondida e inconsciente que estrutura a natureza orgânica, e sim o "cerne irracional" da razão que nos permite compreendê-la (GA, III, 5, 49).

33 O impulso do ser permite, mais bem, pensar em termos dinâmicos a cisão entre absoluto e saber, entre o ser e a sua existência discursiva, ou entre a razão e as suas 
articulações especificas. Essa cisão, na medida em que traz à tona a dimensão prática do saber, permite entender o saber, não apenas como uma simples observação do mundo, e sim como espaço para projetar modelos que permitem ultrapassar a realidade (ou o realismo do sentido comum) por meio da elaboração de novas modalidades para intervir e reestruturar o mundo dado. Esses modelos são autônomos, mas não no sentido da independência de determinações sensíveis. Eles são expressão de uma capacidade de refletir de maneira legítima a transição do mundo dado ao que deve ser, à luz de uma exigência puramente racional. Essa exigência se manifesta à luz da autorreflexão do saber como expressão de uma cobrança de justificação absoluta (conforme Fichte busca mostrar nos textos de filosofia popular e de filosofia aplicada) ${ }^{14}$ que o filósofo não constrói ou produz dentro da filosofia, mas 'amadurece' (ou seja, leva à luz, ou como Fichte fala em um curso sobre, "descobre", GA, II, 13, p. 341) desde o primeiro ato de reflexão sobre o mundo e sobre si mesmo.

Para além de uma linguagem pesada e das argumentações complexas, é possível ver como a confrontação com o realismo racional dá a Fichte os instrumentos conceituais para pensar essa cisão fundamental, em termos de um aprofundamento do idealismo transcendental da doutrina da ciência em uma forma acabada e justificada de realismo ${ }^{15}$. Permanece aberta, portanto, a discussão sobre a legitimidade de Reinhold em aproximar à luz de uma perspectiva filosófica supostamente mais ampla a doutrina da ciência e o realismo bardiliano, apesar dos dois autores recusarem resolutamente toda possibilidade de aproximação ${ }^{16}$.

\section{Abreviações}

GA = "Johann Gottlieb Fichtes Gesamtausgabe der Bayerischen Akademie der Wissenschaften". Ed. R. Lauth, H. Jacob, H. Gliwitzky, Stuttgart-Bad Cannstatt: Fromman-Holzboog, 1962-; I, Werke; II, Nachgelassene Werke; III, Cartas; IV, Nachschriften.

BLU = BLU, I-VI = REINHOLD, K.L., Beyträge zur leichtern Übersicht des Zustandes der Philosophie beym Anfänge des 19. Jahrhunderts. Hamburg: Perthes, 1801-1803.

GEL = BARDILI, G., Grundriss der ersten Logik, gereinget von de Irrthümern bisheriger Logiken überhaupt, der kantischen insbesondere; keine Kritik sondern eine Medicina mentis brauchbar hauptsächlich für Deutschland kritische Philosophie. Stuttgart: Löflund, 1800.

BW = REINHOLD, K. L. - BARDILI, C. G., Reinholds und Bardilis Briefwechsel über das Wesen der Philosophie, München: Leutner. GS = Kants gesammelte Schriften, hrsg. von der Königlich Preussliche Akademie der Wissenschaften, Berlin 1902-

HA = SCHELLING, J.W.F, Historisch-Kritische Ausgabe der Bayerischen Akademie der Wissenschaten, Bd. I, 2, Herausgegeben von Hartmut Buchner und Jörg Jantzen. Unter Mitwirkung von Adolf Schurr und Anna-Maria Schurr-Lorusso. 1980. XI, 428 S.

\section{Referências}

REINHOLD, K. L., Sendschreiben an Lavater und Fichte. Hamburg: Perthes, 1799.

VALENZA, P. Oltre la soggettività finita. Padova: CEDAM, 2003. 
D'ALFONSO, M.V., "Der Trieb des Seins in der Wissenschaftslerhre von 1804", in J.C. Goddard e A. Schnell (org.), L'être et le phénomène, Paris: Vrin, 2009, p. 185-192.

RIVERA DE ROSALES, J., “Die Tranzendentale Logik (1812). Ihr systematischer Ort und ihre Bedeutung“, in «Fichte-Studien», 31, 2008, p. 245-254.

IVALDO, M., "Sulla ontologia di Fichte”, «Aurora», 2015, p. 711-732.

LAUTH, R., Die Frage nach dem Sinn des Daseins, München, 1953.

FERRER, D., “Der Begriff der Existenz und der Gang der Wissenschaftslehre 1805”, in «FichteStudien». 17, 2000, p. 97-119.

FERRAGUTO, F., "Ser, Saber, pensamento: a confrontação de Fichte com o realismo racional de Bardili e Reinhold”, in «Aurora», 2015, p. 819-840.

\section{BIBLIOGRAFIA}

GABRIEL, M., Transcendental Ontology. Essays in German Idealism, New York: Continuum, 2011.

RICHTER, J. P., Clavis fichtiana seu leibgeberiana. Napoli: Cronopio, 2003.

\section{NOTAS DE FIM}

1. Cf. Valenza, 2003, que monstra como essa identificaçõ seja baseada no próprio desenvolvimento do pensamento renholdiano e em uma avalição mais cuidadosa e critica das perspectivas abertas pela doutrina da ciência de Fichte. De fato, para Valenza, a critica de Reinhold a Fichte sustentaria-se sobre a implícita identificação do pensamento de Fichte com a interpretação dele dada por Schelling (pp. 147-149). A validade dessa tese ficaria confirmada pelo afastamento progressivo, no desenvolvimento dos Beyträge de 1801-1803 da confrontação crítica com a doutrina da ciência junto a uma, progressiva também, concentração sobre as demais questões do pensamento schellinguiano evidente, por exemplo nos ensaios de BLU, III, que, porém, não irão entrar no foco do presente artigo.

2. Uma conclusão desse tipo ficaria implícita já na Critica da razão pratica, onde Kant alegaria que podemos falar de determinação livre da vontade, apenas pressupondo uma ação mediadora do arbítrio, pois a vontade, tomada por si, não poderia ser considerada livre (GS, VI, 226). Para Reinhold, ficaria, entretanto, contraditório, afirmar que a liberdade seja ratio essendi da lei moral e no mesmo tempo alegar que apenas o arbítrio seja livre (BLU, II, 111-112).

3. Schelling, HA I, 4164.

4. BLU, II, 112: "Sonach wäre denn also nicht nur die Willküh r(welches auch schon Kant gelehrt hat) Erscheinung des Willens, oder der Freyheit, (Phänomen)sondern auch das moralische Gesetz, als solches, wäre Erscheinung - nämlich die Erscheinung desjenigen Gesetzes, durch welches die absolute Freyheit, oder der reine Wille - nichts als sich selbst ausspricht, und welches nicht das moralische Gesetz, als solches, ist. Endlich wäre eben darum auch die ganze Kantische Autonomie die bloße Erscheinung, und die Vorläuferin, der wahren und eigentlichen Autonomie, welche als die wahre und eigentliche erst durch 
Fichte und Schelling zugleich mit der ganzen übrigen Transcendentalität aufs Reine gebracht ist".

5. Para Reinhold tratar-se-ia de uma tendência de longo prazo na historia da filosofia a qual, na filosofia alemã moderna, e em especial em Kant, Fichte e Schelling, encontra a cima dela ((BLU, II, 115-116).

6. BLU, II, 127. Reinhold reproduz a interpretação do trecho do texto de Fichte Sobre o fundamento da nossa fê em um governo divino do mundo (GA, I, 5, 354), dada no Sendschreiben an Lavater und Fichte (Reinhold, 1799, 23-24).

7. Veja, por exemplo, Reinhold, 1799, p. 71.

8. Reinhold, 1799, p. 6.

9. Nas anotações preparatórias à resenha do Grundriss Fichte encontra-se aberto à perspectiva bardiliana e em especial à critica de Bardili a Kant. De fato, Kant igualaria também pensamento e juízo, e não esclareceria o pensamento na pureza dele. Para Fichte, Bardili teria razão, mas apenas sob a condição de dar um passo a mais: entender pensar, julgar e intuir como atividades unificadas e como expressões de uma única dinâmica de determinação e autodeterminação da razão (GA, II, 5, p. 248).

10. Sobre as implicações realísticas da doutrina da ciência tardia cf. Rivera de Rosales (2007), p. 50-54.

11. GEL, 109. De fato Bardili alega que o impulso através da matéria seja um impulso formal.

12. Uma apresentação sintética das demais etapas do curso fichteano de 1805 foi dada por Ferrer, 2000.

13. Uma apresentação clara da teoria do impulso na doutrina da ciência tardia de Fichte foi dada por D'Alfonso, 2004.

14. Para entender essa noção de 'sentido' veja Lauth, 1953.

15. Uma interpretação da doutrina da ciência tardia como síntese de idealismo e realismo foi dada por Ivaldo, 2015. Para as perspetivas teóricas do realismo na filosofia clássica alemã cf. Gabriel, 2011.

16. Sobre isso cf. Ferraguto, 2015.

\section{RESUMOS}

The paper aims to discuss some elements of Fichte's confrontation with the rational realism of Reinhold and Bardili, developed in the Grundriss der ersten Logik (1800) and in the Beyträge of 1801-1803, which allows to clarify the evolution of the Fichtean thought in relation to the primacy of the practical, affirmed throughout his doctrine of science. Based on a reconstruction of the critiques to the Wissenschaftslehre developed by Bardili and Reinhold in 1801 (\$§ 2-3), the article focuses on the concepts of faith and of Trieb im Sein (\$§ 4-5), developed in the expositions of the Wissenschaftslehre of 1804, 1805 and 1807. In doing this, the paper points out the similarities between the Fichtean perspective and the rational realism already sought by Reinhold in a letter of 1804 .

\section{ÍNDICE}

Keywords: Fichte, Reinhold, Bardili, rational realism, wissenschaftslehre, drive 
AUTOR

FEDERICO FERRAGUTO

Pontificia Universidade Catolica do Paraná, Curitiba 